\title{
PREVALENCE OF INHERITED THROMBOPHILIA IN PATIENTS WITH SEVERE OVARIAN HYPERSTIMULATION SYNDROME
}

\author{
Stepan Machac ${ }^{a}$, Marek Lubuskya, Martin Prochazka ${ }^{a}$, Robert Streda ${ }^{b}$
}

\author{
a Dept. of Obstetrics and Gynecology, University Hospital, Olomouc, Czech Republic \\ b Centre of Assisted Reproduction SANUS, Hradec Kralove, Czech Republic \\ e-mail:machacs@centrum.cz
}

Received: September 5, 2006; Accepted: November 17, 2006

Key words: Ovarian hyperstimulation syndrome/Thrombophilia/Factor V Leiden mutation

Background and objective: To determine the prevalence of markers of inherited thrombophilia in patients with severe form of ovarian hyperstimulation syndrome (OHSS)

Design and methods: Blood samples were analysed for markers of thrombophilia (mutation of factor V - Leiden, mutation of methylentetrahydrofolat reductase (MTHFR) C677T and mutation of prothrombin G20210A). The study group consisted of women who had undergone controlled ovarian hyperstimulation for IVF complicated by severe OHSS (group A, $n=50$ ). Results were compared with two controls groups - women who underwent ovarian hyperstimulation for IVF without developing OHSS (group B, $\mathrm{n}=93$ ) and healthy pregnant women with no history of infertility (group C, $\mathrm{n}=196$ ).

Results: We have found 7 out of 50 patients from group A positive for Leiden mutation (heterozygous) 11 out of 93 from group B (heterozygous), $p=0.71$ OR 1.21 ( 0.393 .70 ) and 10 out of 196 from group $\mathrm{C}$ (heterozygous), $\mathrm{p}=0.03$ OR 3.03 (0.97 9.28). Polymorphism of MTHFR 677T gene was detected in 17 out of 50 patients (heterozygous) from group A, in 36 out of 93 patients from group B (35 heterozygous, 1 homozygous) and in 93 out of 196 patients from the group $\mathrm{C}$ ( 86 heterozygous, 7 homozygous) with no statistical significance.

Conclusions: We found an increased prevalence of factor V Leiden mutation in Czech infertile women. However carriers of Leiden mutation had no enhanced risk of development severe form of OHSS during stimulation.

\section{INTRODUCTION}

Severe form of theovarian hyperstimulation syndrome (OHSS) with an incidence of 0.5 to $1 \%$ per treatment cycle belongs to the most serious complications of methods of assisted reproduction ${ }^{1}$. Typical massive outflow of intravasal fluid into the „third area“ is associated with hemoconcentration (causing hematocrit to increase up to $55 \%$ ), leucocytosis above 25,000 leucocytes per $\mathrm{cm}^{3}$, oliguria and electrolyte imbalance. This clinically serious condition can be complicated by hepatorenal failure or thromboembolic disease. The pathogenesis of the severe form of OHSS is not clear. Most likely, hyperstimulated ovaries produce a substance that provokes vasodilatation of arterioles with subsequent extravasal outflow of a protein-rich fluid. Influence of exogenous or endogenous hCG on the initiation of the entire process was demonstrated ${ }^{2}$. The increase in hematocrit and blood viscosity together with the changes in coagulation parameters are described as the main factors increasing the risk of thrombosis development. Thrombosis prevalence with the severe form of OHSS fluctuates around $0.78 \%{ }^{1}$.

Thrombophilia is an inherited or acquired disorder of hemostatic mechanisms, which is characterised by increased tendency to blood clotting with a subsequent thrombotisation. The inherited forms include resistance to activated protein $\mathrm{C}$ (APC resistance due to muta- tion of V G1691A, Leiden), hyperhomocysteinemia (due to mutation of methylentetrahydrofolat reductase (MTHFR 677T), mutation of prothrombine (G20210A) and deficiency of antithrombine, protein $\mathrm{C}$ and protein $\mathrm{S}$. Antiphospholipide syndrome and attained APC resistance rank among the acquired thrombophilias.

No agreement exists on the relationship between thrombophilia and development of OHSS. Dulitzky et al. published a study covering of 20 patients with the severe form of OHSS, for which they demonstrated a significantly increased prevalence of thrombophilia ${ }^{3}$. In another study covering an equally large group of patients with the severe form of OHSS, Fábreques et al. failed to demonstrate increased prevalence of inherited or acquired thrombophilia ${ }^{4}$.

The aim of this study was to determine the prevalence of inherited forms of thrombophilia (mutation of the factor V Leiden, mutation of G20210A prothrombine, mutation of MTHFR C677T) in patients with the severe form of OHSS.

\section{DESIGN AND METHODS}

\section{Study group A}

50 infertile women aged 22 to 40 (mean 32.0, median 33.0), in which ovarian stimulation for IVF was compli- 
cated by development of the severe form of OHSS. The patients were stimulated by a long protocol or by protocol using GnRH agonists. In all the patients, the severe form of OHSS was diagnosed according to the criteria published by Navot et al. ${ }^{1}$. The main subjective complaints included dyspnoea and abdominal pains. Larger volumes of ascitic fluid necessitating puncture and an ovary hypertrophy up to $10 \mathrm{~cm}$ in diameter were diagnosed by ultrasound examination. Laboratory finding revealed presence of leucocytosis (more than 20,000 leucocytes per $\mathrm{cm}^{3}$ ), hemoconcentration (hematocrit above $40 \%$ ) and changes in hepatic and renal functions.

\section{Control group $B$}

93 infertile women aged 22 to 38 (mean: 31.1; median: 31.0) treated by IVF method, whose stimulation was not complicated by development of the OHSS. All the patients were stimulated by a long protocol or by protocol with GnRH agonists.

\section{Control group $C$}

196 healthy women aged 21 to 35 (mean: 28.8; median: 29.0) with physiological course of pregnancy who gave birth at the Dept. of Obstetrics and Gynecology in Olomouc. Women treated for infertility were not included in the group. The examinations were performed in the $3^{\text {rd }}$ trimester of pregnancy or after delivery.

Molecular-genetic examination for thrombophilia mutations were performed in all the women. Multiplex allelaspecific polymerase chain reaction (MS PCR) was applied after a complex determination of mutations of FV 1691 G-A (Leiden), prothrombine 20210 G-A and MTHFR 677 C-T. Electrophoresis on Spreadex 400 (Elchrom Scientific) high-resolution gel was used to separate the PCR reaction products. Staining by $\operatorname{Sybr}^{\circledR}$ Green (1 : 10000, Molecular Probes) was used to visualize the PCR reaction products separated by the electrophoresis.

Statistical evaluation was performed using Statistica v. 6 software. Values of $p<0.05$ were regarded as statistically significant.

\section{RESULTS}

We have found heterozygous form of the factor $\mathrm{V}$ (Leiden) mutation in 7 women of the group A $(7 / 50)$, in 11 women of the control group B $(11 / 93)(p=0.71$; OR $1.21 ; 95 \% \mathrm{Cl} 0.39$ to 3.70$)$ and in 10 women of the control group C $(10 / 196)(\mathrm{p}=0.03$; OR 3.03; $95 \% \mathrm{Cl}$ 0.97 to 9.28 ) (Tab 1,2$)$.

We have found the heterozygous form of the MTHFR C677T mutation in 17 women of the group A $(17 / 50)$, in 36 women of the control group $B(36 / 93)(p=0.58$; OR $0.82 ; 95 \% \mathrm{Cl} 0.37$ to 1.78$)$ and in 86 women of the control group C $(86 / 196)(\mathrm{p}=0.21$; OR $0.66 ; 95 \% \mathrm{Cl}$ 0.33 to 1.32 ) (Tab 1,2 ).

The homozygous form of the MTHFR C677T mutation was found in none of the women of the group
A $(n=50)$; it was found in one woman of the control group B (1/93) and in 7 women of the group C (7/196). Mutation of the G20210A prothrombin was found in none of the women (Tab 1, 2).

The heterozygous form of the factor $\mathrm{V}$ (Leiden) mutation was found in 11 women of the control group B (11/93) and in 10 women of the control group C (10/196) ( $\mathrm{p}=0.03$; OR 2.50; $95 \%$ CI 0.94 to 6.65 ) (Tab 3).

The heterozygous form of the MTHFR C677T mutation was found in 36 women of the control group B (36/93) and 86 women of the control group C (86/196) $(\mathrm{p}=0.41$; OR 0.81 ; $95 \%$ CI 0.47 to 1.38$)$ (Tab 3$)$.

\section{DISCUSSION}

Thromboses and the thromboembolic disease are among the most serious complications of stimulation in the assisted reproduction techniques. Most frequently, they occur in association with development of the severe form of ovarian hyperstimulation syndrome (OHSS). Thromboses occur only in low number of the affected patients and it is unclear, in which way the severe form of OHSS increases the risk of their development. Hemoconcentration may contribute to the development of thrombosis, but it is not the only cause ${ }^{4}$. Prothrombotic role of high estrogen levels has been demonstrated in women using oral contraceptives and during pregnancy ${ }^{5}$. Biron et al. monitored the correlation between estrogen levels and changes in coagulation parameters in patients with the severe form of $\mathrm{OHSS}^{6}$. However, they failed to confirm the expected relationship.

Kodama et al. stated a statistically significant increase of fibrinogen level and decrease of antithrombin and alpha 2 antiplasmin levels in patients with the severe form of $\mathrm{OHSS}^{7}$. They also demonstrated high levels of D-dimers and thrombin - antithrombin complexes, which reflect activation of the coagulation cascade. On the other hand, Delvigne et al. failed to demonstrate any changes in coagulation parameters except an increase of fibrinogen level in a group of 25 patients with the severe form of $\mathrm{OHSS}^{8}$.

Thrombophilias constitute a group of inherited or acquired blood coagulation disorders, which also increase the risk of thrombosis development. Typical features of thrombophilias include occurrence of venous thromboses before the age of 45 , occurrence of thromboses in abnormal locations and their repeated occurrence. Prevalence of heterozygous forms of F V (Leiden) mutations varies across European countries ranging from $2 \%$ in the south to $10 \%$ in Nordic countries ${ }^{9}$. This mutation increases the risk of development of venous thrombosis eight times. Prevalence in the population of Europe is reported to range from 30 to $40 \%$ for the MTHFR 677 (heterozygous) mutation and from 2 to $2.8 \%$ for the G20210A prothrombin mutation ${ }^{10}$. Findings of these mutations are very rare in the populations of Africa and Asia ${ }^{4}$.

Presence of thrombophilic mutations increases the risk of venous thromboses and thromboembolic disease during pregnancy with a statistical significance ${ }^{4}$. In case 
Table 1: Comparison of thrombophilia prevalence in patients with OHSS and IVF treated patients

\begin{tabular}{|l|c|c|c|c|}
\hline & $\begin{array}{c}\text { Study group A } \\
(\mathrm{n}=50)\end{array}$ & $\begin{array}{c}\text { Control group B } \\
(\mathrm{n}=93)\end{array}$ & $\mathrm{p}$ & Odds ratio \\
\hline $\begin{array}{l}\text { F V Leiden } \\
\text { mutation }\end{array}$ & 7 & 11 & 0.71 & $1.21(0.39-3.7)$ \\
\hline $\begin{array}{l}\text { MTHFR 677 mutation } \\
\text { (heterozygous) }\end{array}$ & 17 & 36 & 0.58 & $0.82(0.37-1.78)$ \\
\hline $\begin{array}{l}\text { MTHFR 677 mutation } \\
\text { (homozygous) }\end{array}$ & 0 & 1 & 0.66 & $1.84(0.0-69.1)$ \\
\hline
\end{tabular}

Table 2: Comparison of thrombophilia prevalence in patients with OHSS and in healthy fertile women

\begin{tabular}{|l|c|c|c|c|}
\hline & $\begin{array}{c}\text { Study group A } \\
(\mathrm{n}=50)\end{array}$ & $\begin{array}{c}\text { Control group C } \\
(\mathrm{n}=196)\end{array}$ & $\mathrm{p}$ & Odds ratio \\
\hline F V Leiden mutation & 7 & 10 & 0.03 & $3.03(0.97-9.28)$ \\
\hline $\begin{array}{l}\text { MTHFR 677 mutation } \\
\text { (heterozygous) }\end{array}$ & 17 & 86 & 0.21 & $0.66(0.33-1.32)$ \\
\hline $\begin{array}{l}\text { MTHFR 677 mutation } \\
\text { (homozygous) }\end{array}$ & 0 & 7 & 0.56 & $0.54(0.02-4.53)$ \\
\hline
\end{tabular}

Table 3: Comparison of thrombophilia prevalence in infertile patients without OHSS and in healthy fertile women

\begin{tabular}{|l|c|c|c|c|}
\hline & $\begin{array}{c}\text { Control group B } \\
(\mathrm{n}=93)\end{array}$ & $\begin{array}{c}\text { Control group C } \\
(\mathrm{n}=196)\end{array}$ & $\mathrm{p}$ & Odds ratio \\
\hline F V Leiden mutation & 11 & 10 & 0.03 & $2.50(0.94-6.65)$ \\
\hline $\begin{array}{l}\text { MTHFR 677 mutation } \\
\text { (heterozygous) }\end{array}$ & 36 & 86 & 0.41 & $0.81(0.47-1.38)$ \\
\hline $\begin{array}{l}\text { MTHFR 677 mutation } \\
\text { (homozygous) }\end{array}$ & 1 & 7 & 0.23 & $0.29(0.01-2.42)$ \\
\hline
\end{tabular}

of pregnant women, they have been regarded relating to repeated pregnancy loss, development of preeclampsia, growth retardation of foetus and placenta abruption ${ }^{10-13}$.

Increased prevalence of thrombophilic conditions has also been reported in patients with repeated IVF infertility treatments. Azem et al. diagnosed some of the inherited forms of thrombophilia in $26.7 \%$ women with four and more IVF cycle failures $(n=45)^{14}$. For the control group of healthy women $(n=44)$, it was only $9.1 \%$ patients.

In our group, we have demonstrated an increased prevalence of the heterozygot form of the factor $\mathrm{V}$ (Leiden) mutation. However, carriage of this mutation does not imply a higher risk of development of the severe form of OHSS for a patient during stimulation in an IVF programme. We have failed to confirm the results published by Dulitzky et al. who demonstrated thrombophilia in $85 \%$ patients $(17 / 20)$ with the severe form of $\mathrm{OHSS}^{3}$. On the other hand, Fábregues et al. failed to demonstrate thrombophilia in any of their patients diagnosed with the severe form of OHSS $(n=20)^{4}$. In the control group of IVF treated infertile patients $(n=40)$, the occurrence of thrombophilia was also at minimum $(1 / 40)$. By virtue of these results, the authors did not recommend screening examination of thrombophilic mutations to perform in infertile patients.

A question remains, whether the increased prevalence of thrombophilic mutations in infertile patients may be the cause of their reduced fertility. In their study, Martinelli et al. compared the prevalence of thrombophilia in infertile patients with an IVF cycle failure $(n=234)$ with that in a control group of patients that impregnated spontaneously $(n=234)^{15}$. The heterozygous form of the factor $\mathrm{V}$ (Leiden) mutation was present in $5 \%$ patients of the study group compared to $2 \%$ patients of the control group. The heterozygous form of the prothrombin G20210A mutation was present in $3 \%$ patients of the study group com- 
pared to $6 \%$ patients of the control group. No relationship between IVF failure and presence of thrombophilia was demonstrated in this work.

Vaquero et al. published similar results ${ }^{16}$. They also failed to find an increased occurrence of thrombophilia in patients with at least one IVF cycle failure $(n=51)$. Influence on the fertility of carriers of thrombophilic mutations was not unequivocally demonstrated.

Our results of our study revealed that prevalence of the heterozygous form of factor $\mathrm{V}$ (Leiden) mutation is increased in infertile patients. However, carriage of this mutation does not increase the risk of development of the severe form of OHSS during IVF programme stimulation ${ }^{17}$. Routine examination of inherited thrombophilic mutation is not indicated for infertile patients.

\section{ACKNOWLEDGEMENTS}

This study was supported by the grant of IGA Ministry of Health of the Czech Republic NR 7810-3 (2004).

\section{REFERENCES}

1. Navot D, Bergh P, Leufer N. Ovarian hyperstimulation syndrome in novel reproductive technologies: prevention and treatment. Fertil Steril 1992; 58:249-61.

2. Brinsden PR, Wada I, Tan SL, Balen A, Jacobs HS. Diagnosis, prevention and management of ovarian hyperstimulation syndrome. Brit J Obstet Gynecol 1995; 102:767-72.

3. Dulitzki M, Cohen SB, Inbal A, Seidman DS, Soriano D, Lidor A, et al. Increased prevalence of thrombophilia among women with severe ovarian hyperstimulation syndrome. Fertil Steril 2002; 77:463-7.

4. Fabregues F, Tassies D, Reverte JC, Carmona F, Ordinas A, Balasch J. Prevalence of thrombophilia in women with severe ovarian hyperstimulation syndrome and cost-effectiveness of screening. Fertil Steril 2004; 81:989-95.
5. Paseka J, Unzeitig V, Cibula D. Mutace faktoru V Leiden u uživatelek hormonální antikoncepce. Ces Gynek 2000; 65:156-9.

6. Biron $\mathrm{CH}$, Galtier-Dereure F, Robesandratena H, Bernard I, Hodon B. Hemostasis parameters during ovarian stimulation for in vitro fertilisation: results of a prospective study. Fertil Steril 1997; 67:104-9.

7. Kodama H, Fukada J, Karube H, Matsui T, Shimuzu Y, Tanaka T. Characteristics of blood hemostatic markers in a patient with ovarian hyperstimulation syndrome who actually developed thromboembolism. Fertil Steril 1995; 64:1207-9.

8. Delvigne A, Kostyla K, De Leener A. Metabolic characteristics of women who developed ovarian hyperstimulation syndrome. Hum Reprod 2002; 17:1994-6.

9. Svensson PJ, Dahlback . Resistence to activated protein C due to mutated factor $\mathrm{V}$ as a novel cause of inherited thrombophilia. Haematologia 1995; 80:344-56.

10. Tsanadis G, Vartholomatos G, Korkontzelos I, Avgoustatos F, Kakosimos G, Sotiriadis A. Polycystic ovarian syndrome and thrombophilia. Hum Reprod 2002; 17:314-9.

11. Alfirevic Z, Mousa HA, Martlew V. Postnatal screening for thrombophilia in women with severe pregnancy complications. Obstet Gynecol 2001; 97:753-59.

12. Alfirevic Z, Roberts D, Martlew V. How strong is the association between maternal thrombophilia and reverse pregnancy outcome? A systematic review. Eur J Obst Gynecol Reprod Biol 2002; 101:614.

13. Lindquist $P$, Dählback B, Marsal K. Thrombotic risk during pregnancy: A population study. Obstet Gynecol 1999; 94:595-9.

14. Azem F, Many A, Ben Ami I, Yovel I, Amit A, Lessing J B, et al. Increased rates of thrombophilia in women with repeated IVF failures. Hum Reprod 2004; 19:368-70

15. Martinelli I, Taioli E, Ragni G, Levi -Setti P, Passamonti SM, Battaglioli T. Embryo implantation after assisted reproduction procedures and maternal thrombophilia. Haematologica 2003; 88:789-93.

16. Vaquero E, Lazzarin N, Caserta D, Valensise H, Baldi M, Moscarini $\mathrm{M}$, et al. Diagnostic evaluation of women experiencing repeated in vitro fertilisation failure. Eur J Gynecol Reprod Biol 2005; 10:1253-5.

17. Machac S, Lubusky M, Prochazka M. Prevalence of Inherited Thrombophilia in Patients with Severe Ovarian Hyperstimulation Syndrome. Proceedings of the $22^{\text {nd }}$ ESHRE annual meeting, 2006, 18-21 June; Prague, Czech Republic. Oxford University Press, 2006. p. i143-i144. 